
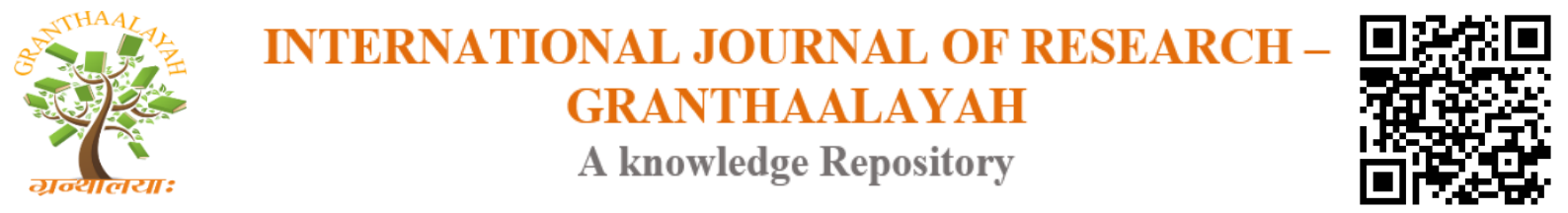

Social

\title{
FORM-FOCUSED INSTRUCTION: ISOLATED OR INTEGRATED?
}

\author{
Hussam Abdulaziz *1 \\ ${ }^{* 1}$ English Language and Literature, Istanbul Aydin University, Turkey
}

\begin{abstract}
Research has shown that attracting foreign/second language (L2) learners' attention to form in communicative-based classrooms will help them improve their accuracy. Form-Focused Instruction (FFI)- teaching the form of the language while the main focus of the instruction is still the meaning- seems to be the way to insert the form instruction into Communicative language teaching. This study investigates whether the L2 learners of English and English language teachers prefer the isolated or integrated FFI that are the two ways of attracting the learner's attention to the form of the language in meaning-based activities. Language teaching has shifted from grammar-based instruction represented in grammar-translation method to meaning-based instruction represented in the Communicative Language Teaching, and then to the most recent phase where form and meaning are taught at the same time represented in FFI. The purpose of this work is to find out how the students want to learn the English grammar and then to match their preferences with those of their teachers. The results showed that both groups significantly preferred the integrated FFI over the isolated one.
\end{abstract}

Keywords: Form-Focused Instruction; Isolated FFI; Integrated FFI.

Cite This Article: Hussam Abdulaziz. (2019). "FORM-FOCUSED INSTRUCTION: ISOLATED OR INTEGRATED?.” International Journal of Research - Granthaalayah, 7(6), 276-287. https://doi.org/10.29121/granthaalayah.v7.i6.2019.804.

\section{Introduction}

The shift in language teaching from grammatical competence to communicative competence has created a big change in the ways how language is learned and taught. Communicative Language Teaching (CLT) came as a response to this change. However, when research findings showed that CLT has developed lack of accuracy among learners (Doughty \& Williams, 1998), Form-Focused Instruction (FFI) came as a response. It has created a balance between communicative competence and grammatical competence so learners can gain fluency and accuracy at the same time.

Form instruction has three types: focus on forms, planned focus on form, and incidental focus on form. The first type, focus on forms, is when primary focus is on the forms of the language; that is to say, the focus of teaching is accuracy, not fluency. This type of form instruction is described as intensive teaching of grammatical structures that usually happens in sessions separated from 
communicative activities. In the two other types, the name 'focus on form' entails that the primary focus of instruction is meaning and communicative competence. The planned focus on form is where teachers predetermine the grammatical structures that they want to attract the learners' attention to; this can be done through focused tasks where the focus on form is intensive. The third type, the incidental one, is not predetermined. It is based on the learners' linguistic needs in communicative activities. In this specified approach, the grammatical structures can be random so it can also be described as an extensive approach of form instruction (Ellis, 2001). There is widespread disagreement among researchers over which type is the most beneficial in helping to develop implicit knowledge. For example, Dekeyser (1998) argued that Focus-on-forms was the most efficient one. He believes that form is learned better while Promoting the explicit knowledge; this could happen through focus-on-forms. On the other hand, Long (1991) and Doughty (2001) opposed Dekeyser and backed the focus on form approach. They argued its effectiveness in facilitating interlanguage development because learners best acquired their implicit knowledge when paying attention to form whilst working on understanding and creating meaningful conversations (Ellis, 2006).

FFI draws learners' attention to the grammatical features of the language in communicative-based activities; the main focus of teaching is communicative competence. The two questions that received quite a lot of attention among teachers and researchers were how best to draw learners' attention to form and when to do that. While speaking about how to focus on form, we are speaking about implicit and explicit types of form instruction; as for the timing of focusing on form in a communicative-based context, we mean the integrated and isolated types of FFI (Spada, 2017).

Researchers were divided into three opposing positions; all concerned with whether or not explicit knowledge would be transformed into implicit knowledge. The first stance is that explicit and implicit knowledge are totally separated, and they do not interface (Krashen, 1981). The second stance opposes the first one stating that explicit knowledge converts to implicit knowledge when it is used in a communicative practice (Dekeyser, 1998). The third stance, the weak interface stance, states that explicit knowledge converts to implicit knowledge when the learners are ready to obtain the language features (Ellis, 2001). What most of the researchers have agreed on is that communicative competence is a matter of implicit knowledge, so one does not need explicit knowledge in order to be fluent; at the same time, explicit instruction of grammatical structures is more effective than implicit one; it helps learners convert these structures into implicit knowledge. Furthermore, it develops learners' analytical skills of the language forms (Dekeyser, 1998, Norris \& Ortega, 2000; Spada \& Tomita, 2010).

The second question that attracted the attention of both the teachers and researchers is when to draw learners' attention to the grammatical features of the language in communicative-based classes. Spada and Lightbown (2008) conceptualized isolated FFI and Integrated FFI. These two types of instruction continue to draw the learners' attention to the form of the language whilst the main focus is the communicative activities. Both of them can be described as an explicit instruction of linguistic forms in a meaning based classroom (Ellis, 2016). The difference between integrated \& isolated FFI is clarified by their names; the integrated FFI is where learners pay attention to the structure or the form of the language during the communicative activities. The isolated FFI is where the form or the grammatical structures of the language is being taught in isolated sessions from the communicative activities. Both types include attention to form and meaning. The main 
difference between these two types is not how to pay attention to grammatical features, but rather when to pay attention to grammatical features.

The extensive research of Spada and Lightbown, who came up with these two conceptualizations, indicated after lengthy studies of both concepts that these two types complement each other and that there is no need to exclusively follow just one of them. The research stated that each type was effective for different aspects of language learning (Valeo \& Spada, 2015).

Among the literature that supports the isolated FFI, there are researchers who see the isolation of form from communicative activities as a more natural way of teaching, and it suggests that it suits traditional pedagogical practices. Another argument that supports the isolation of form is based on the fact that humans have restricted ability so the combination of both meaning and form can be difficult for some learners to grasp (VanPatten, 1990). A third argument is that the separation of form instruction from the communicative activities will not interrupt the communicative interactions between learners, but instead keep them motivated (Raimes, 2002). The fourth argument is that isolated FFI is more effective when the targeted language features are not salient and not easily noticed by the learners. The last point indicates that isolated FFI is more helpful when the learners share the same first language and when the level of all the learners is low, and therefore they struggle together with understanding the input they are exposed to. In these cases, it is supposedly harder for the learners to connect between both meaning and form (Spada, 2017). On the other hand, many studies and arguments claim that integrated FFI is more efficient. One of the arguments stated that integrating the form instruction in the communicative activities, where the students will get immediate feedback about form, will be achieving two aims in one session. Another argument that supports form integration is that form instruction will then occur exactly when it is needed during the learning session (Spada \& Lightbown, 2008). A third argument is that integrated FFI is more effective in teaching complicated grammar--those grammatical structures which cannot simply be explained in the isolated way of from instruction (Spada, 2017). One research done by Valeo and Spada in (2015) investigated the preference of integrated or isolated FFI amongst 500 learners and 100 teachers; a clear preference for integrated form instruction was found. At the same time, both learners and teachers valued isolated FFI. Another research conducted by Bulut and Algül (2017) investigated the impact of proficiency level, gender, and university type on the preference between isolated and integrated FFI among local adult learners; the results showed that the learners preferred integrated FFI and valued isolated simultaneously FFI.

Spada, et al. (2014) examined the validity of Transfer Appropriate Processing Theory within form instruction. The study focused on investigating how the timing of implementing form instruction affected learners' production of the targeted language. The study showed that there was no difference between learners' production of the targeted language whether they learned it during isolation or integration as long as they got their form instruction embedded within communicative based instruction.

\section{Methodology}

To contribute to the research body and further develop the findings in this area of research we conducted a descriptive study based on a survey method investigating the preferences of Foreign 
Language Learners (FLLs) and Foreign Language Teachers (FLTs) between integrated and isolated FFI. We used questionnaires developed and validated by Spada after getting her permission. The two research questions are:

1) What type of FFI do the teachers and learners prefer, Isolated or Integrated?

2) Do their FFI type preferences match?

This research was carried out at Istanbul Aydin University (IAU) English Preparatory School. The total number of participants was 150, combining both 100 learners and 50 teachers. Out of 100 learners, 74 of them completed the questionnaires. Additionally, out of 50 teachers, 31 completed the questionnaires.

All the students were adult FLLs of English who completed their high school and started the English Preparatory School at IAU. More than half of the student participants were males (51\%). Most of the students (75\%) were the native speakers of Turkish, and the other $25 \%$ came from countries such as Syria, Iraq, Yemen etc. where Arabic is the native tongue. The majority of them $(78 \%)$ were enrolled in intermediate level classes.

All the participating teachers were teaching at IAU English Preparatory School, the majority of them $(77 \%)$ were female teachers. The percentage of teachers who were under 29 years old was $67 \%$. Most of them (93\%) were teaching intermediate level classes. Twenty-nine teachers (90\%) had up to 10 years' experience. Two teachers had Ph.D. degrees, and twelve others had MA degrees; however, the majority of them (54\%) had a BA in English Language Teaching. Almost all the teachers $(93 \%)$ received their teaching qualification with a focus on communicative methodology. Table 1 includes further details about the profile of the participants.

Table 1: Teachers and Students' Profile Table

\begin{tabular}{|l|l|l|}
\hline Data & Teachers $(\mathbf{n}=\mathbf{3 1})$ & Students $(\mathbf{n}=\mathbf{7 4})$ \\
\hline Gender & Female & Male \\
& $77 \%(\mathrm{n}=24)$ & $51 \%(\mathrm{n}=38)$ \\
\hline Age & Under 29 & Under 25 \\
& $67 \%(\mathrm{n}=21)$ & $100 \%(\mathrm{n}=74)$ \\
\hline Class' level & Intermediate & Intermediate \\
& $93 \%(\mathrm{n}=29)$ & $78 \%(\mathrm{n}=58)$ \\
\hline Teachers' experience & Under 10 years & -- \\
& $90 \%(\mathrm{n}=28)$ & \\
\hline Education & BA. 54\% $(\mathrm{n}=17)$ & High school \\
& MA. 30\% $(\mathrm{n}=11)$ & $100 \%(\mathrm{n}=74)$ \\
& PhD. 1\% $(\mathrm{n}=2)$ & \\
\hline Teacher's method & Communicative & -- \\
& $83 \%(\mathrm{n}=26)$ & \\
\hline
\end{tabular}

This study used the questionnaire developed by Spada (2015). Permission for its use was received directly from her. The teachers and the learners were asked to respond to a set of statements in 5point Likert scale. The statements were designed to find out whether participants preferred to follow the isolated or the integrated approach of FFI. The teachers' questionnaire contained 22 questions. Half of them reflect the integrated approach, and the other half reflected the isolated 
one. The questionnaire given to the learners contained 26 questions. Thirteen was about the integrated approach, and the rest investigated the isolated one. In addition to the 5-Likert scale statements, the questionnaire included an open-ended question where participants were asked to give their comments and share their own ideas about the timing of FFI.

\section{Results and Discussion}

To check the reliability of our obtained data, we used Cronbach's Alpha, a statistical test that measures the reliability of data. Table 2 below illustrates the main results of testing for reliability in the teachers' and learners' questionnaires. After applying this test, Item 13 was deleted from the teachers' questionnaire; because Cronbach's Alpha analysis indicated that this item was inconsistent with the other items. All the results were over (.70) indicating the reliability.

Table 2: Reliability Test

\begin{tabular}{|l|l|l|l|}
\hline Questionnaire & Item type & $\mathbf{N}$ & Reliability (a coefficient) \\
\hline Teachers $(n=31)$ & Integrated & $10^{*}$ & .804 \\
& Isolated & 11 & .862 \\
\hline Students $(n=74)$ & Integrated & 13 & .791 \\
& Isolated & 13 & .786 \\
\hline
\end{tabular}

The responses were calculated as mean scores. Excel 2010 was used to statistically analyze the whole data, including the Data Analysis Tool Pak add-on feature. Each set of questions were analyzed separately: Teachers integrated \& isolated, and Learners integrated \& isolated.

The mean (M) and standard deviation (SD) obtained from the questionnaire given to the teachers were statistically analyzed separately for each set: integrated and isolated. Numerically the difference between the two means was clear: integrated $(\mathrm{M}=2.98, \mathrm{SD}=0.44)$, isolated $(\mathrm{M}=1.98$, $\mathrm{SD}=0.63)$. This indicates that the teacher participants prefer the integrated FFI substantially more than the isolated FFI. Table 3 shows the mean results for each group. Figure 1. shows the results in a chart to illustrate the difference between the two groups of questions in a graphical form.

Table 3: Teachers' Questionnaires Descriptive Statistics

\begin{tabular}{|l|l|l|l|}
\hline & Item Type & M & SD \\
\hline Teacher $(n=31)$ & Integrated & 2,98 & 0.44 \\
& Isolated & 1,98 & 0.63 \\
\hline
\end{tabular}




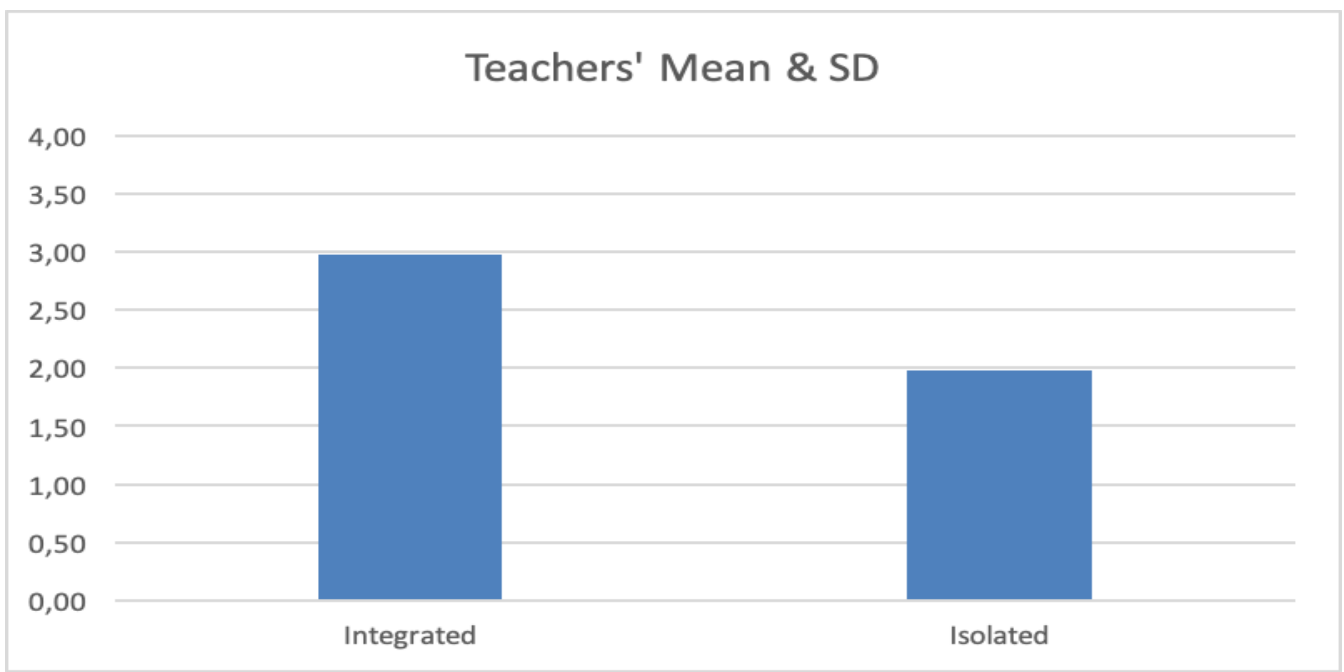

Figure 1: Mean and Standard deviation for Teachers.

The findings show that the teachers prefer integrated FFI. To make sure that this result is statistically significant, we carried out a dependent samples t-test. With means and standard deviations as follows: integrated $(\mathrm{M}=2.98, \mathrm{SD}=0.44)$ and isolated $(\mathrm{M}=1.98, \mathrm{SD}=0.63)$, the $\mathrm{t}-$ test result is: $(\mathrm{p}<0.00)$. the $\mathrm{p}$-value indicates that the difference between the two means is statistically significant. The Table 4 below shows further details for the t-test results.

Table 4: T-test Results for Teacher Questionnaires, Integrated \& Isolated

\begin{tabular}{|l|l|l|l|l|l|l|}
\hline & M & SD & T stat & T critical & df & P-value \\
\hline Integrated & 2.98 & 0.44 & 6.02 & 1.69 & 30 & 0.00 \\
\cline { 1 - 4 } Isolated & 1.98 & 0.63 & & & & \\
\hline
\end{tabular}

The qualitative data obtained from the teachers reflected their opinions on how the form to be taught in communicative-based classes. Eight teachers out of thirty-one provided their comments. Most of the comments elaborate on the participants' responses; however, some of them added different and new views for the ways to introduce the form in CLT:

T1: "I strongly believe that the methodology such as Grammar-Translation or CLT depends on the level of the target students. Considering the non-degree students who have a restricted knowledge of English grammar or even their native tongue grammar, I think they should start digesting the grammar rules first. After that, we [should] encourage them to put these rules into sentences through writing or speaking." T1 recognizes that it is preferable to start with educating students on language form and then move to practicing communication in dealing with non-academic or beginner learners.

T2: "There is no one way to teach language. The best way is to combine all alike [methods] and use them at the same time."

T3: "Teaching grammar through communication is, in my opinion, optimal. The students though prefer to have it isolated, to know all forms before they start using it well and with confidence. I think we can never give enough examples as they always ask for more. I have been lucky to get really ambitious and hardworking students year after year. CLT is my training as well as most of 
my method, but I use all methods, grammar-translation, audio-lingual, silent way etc. I think the best of all methods make excellent lessons." T3 has a holistic approach to teaching language, in combining many individual methods within a communicative approach.

T4: "Unfortunately, [the entire] system is based on grammar drills, and the students get used to it. I think the school should emphasize the communication function of language. Something should be changed, especially our exams. We should give more importance to production. The grammar part in the exams does not measure student knowledge. It is more about memorization, not learning or acquiring." T4 seems to indicate that she believes learning grammar will not help in acquiring the language. Language acquisition is a process of communicating, it is with the practice of communicating that language can be used and learnt simultaneously (Richards, 2006). It is a fact that grammar forms part of the structure of the languages, and it can provide important rules that guide the use of a language, however using grammar is very different from using the language. It is through speaking and listening that we can acquire the native use of a foreign language (Y1ldırım \& Y1ldırım, 2016).

T5: "Teaching grammar while communicating is the best way. Grammar rules are secondary tools. What makes us speak a language is our efficiency of communication."

T6: "Each student has a different way of learning. For some, it is better to use content-based instruction; on the other hand, some students want to see the new structure \& grammar rule solely first. That is why I try to apply them both when I am teaching grammar."

T7: "Teaching grammar is a broad concept. To me, the best way to teach a language is in a communicative environment. But sometimes we need more focus on form, especially with certain grammar points. We may need to drift apart from our context and move to grammar teaching. Therefore, I find it difficult to say it is 'the best' way to teach grammar in a meaningful context. The ideal is teaching every aspect in an enriched meaningful context, but because of time constraints or other issues we can't make it happen unfortunately."

T8: "I believe besides the in-class activities, we need to give the students certain tasks in which they need to use grammar in context. I think giving writing assignments or requesting brief presentations from the students may be a good way for them to incorporate the grammar they learn in class"

Considering all these comments, we can draw the following conclusions. Only three teachers (T3, T4, T5) out of eight teachers confirmed that the integrated approach of instruction is seen as the optimal way to teach a foreign language. For example, T3 said: "Teaching grammar through communication is, in my opinion, optimal." Likewise, T4 said: "I think the school should emphasize the communication function of language." Lastly, T5 commented: "teaching grammar while communicating is the best way." These comments are evidence that in a classroom atmosphere it is important, if not fundamental to ensure a CLT is utilized.

Five teachers, (T1, T2, T6 T7, and T8), commented that using both approaches simultaneously is better approach to take. They all agreed that pairing a communicative environment with some focus on grammar was preferable and that it is more important to be flexible in the approach and 
to address particular grammar rules, the individual student's needs, and the differing levels of each student.

On the other hand, three out of eight teachers confirmed their support for the integrated type of FFI, while five out of eight stayed neutral. These five stated that there was no one way of teaching form and that both the integrated and the isolated were important. The key was choosing between them depending on the target students, their level, and their knowledge.

The data obtained from the learners show that they prefer integrated FFI: integrated $(\mathrm{M}=3.50$, SD $=0.68)$, isolated $(\mathrm{M}=3.23, \mathrm{SD}=0.68)$, indicating the homogeneity of the answers. At the same time from the mean of the isolated statements (3.23) we can see that learners value Isolated FFI. Table 5 presents the results in numbers and Figure 2 illustrates the results in a graphic image.

Table 5: Learners M \& SD Results for Integrated and Isolated

\begin{tabular}{|l|l|l|l|}
\hline & Item Type & M & SD \\
\hline Learners $(\mathrm{n}=74)$ & Integrated & 3.50 & 0.68 \\
& Isolated & 3.23 & 0.68 \\
\hline
\end{tabular}

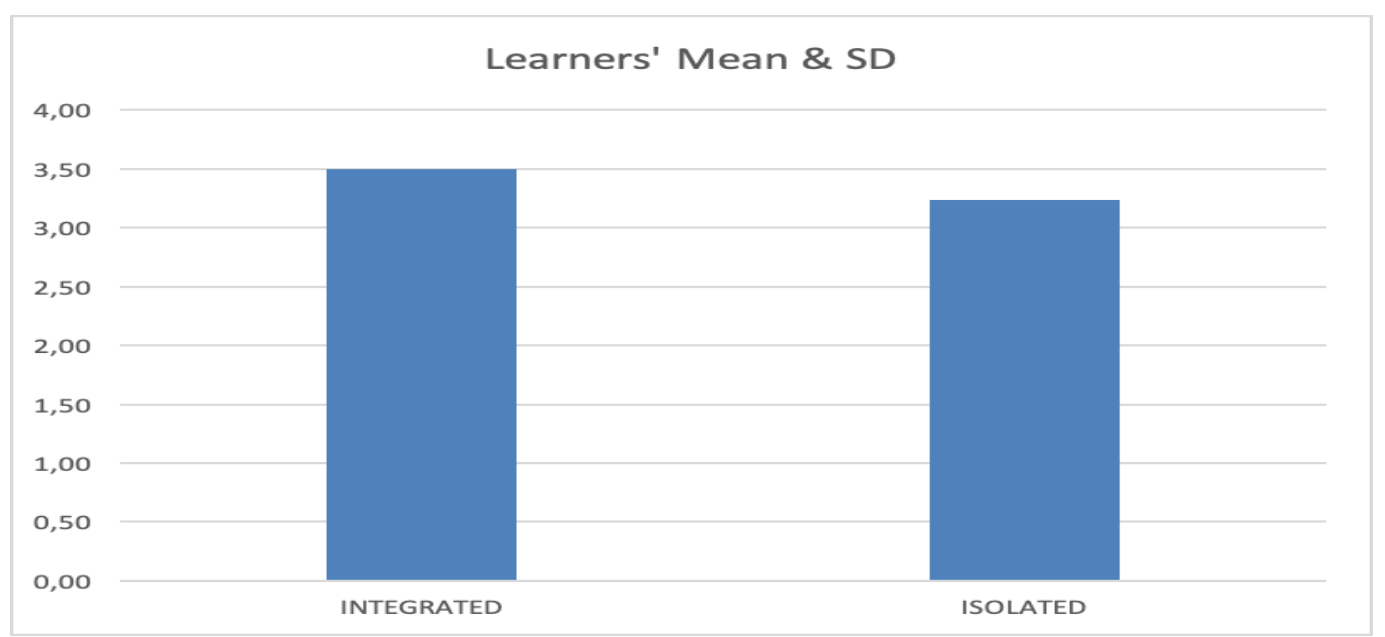

Figure 2: Mean \& Standard Deviation for Learners.

The t-test of the difference between the means of two dependent samples was conducted again to see if the findings are statistically significant. The two means and standard deviations are: integrated $(M=3.50, S D=0.68)$ and isolated $(M=3.23, S D=0.68)$, the result is: $(\mathrm{p}<0.01)$ which indicates that the difference between the two means is statistically significant. Table 6 presents further details of the t-test results.

Table 6: T-test for Learners-Questionnaires, Integrated \& Isolated

\begin{tabular}{|l|l|l|l|l|l|l|}
\hline & M & SD & t Stat & t Critical & df & P-value \\
\hline integrated & 3.50 & 0.68 & 2.51 & 1.66 & 73 & 0.007 \\
\hline isolated & 3.23 & 0.68 & & & & \\
\hline
\end{tabular}

As for the qualitative data obtained from the students, only ten students commented in the openended questions section out of seventy-four participants. In responding to the open-ended question 
that asks learners about their beliefs and preferences for learning grammar, we received the following answers:

Learner 1 (L1): "When we want to learn grammar or improve our skills we should communicate with each other." L1 prefers communication in learning grammar.

L2: "It should be something like 'live and learn'. Theoretical learning is too bad I reckon." L2 believes we should live the language to be able to learn it. This is a form of 'experiential-learning'. Each language has a different grammatical syntax, and thus a different mindset and way of thinking. To speak that language one needs to practice it in a communicative atmosphere (Schouwstra, 2012).

\section{L3: "I learn it [better] while [communicating]."}

L4: "we should communicate with each other to learn grammar."

L5: "less grammar lessons, please." From L5's comment we can speculate that a lot of grammar instruction involving model repetition and rule. memorization makes the learning process boring and complicated (Larsen-Freeman, 1997).

L6: "learning grammar is one of the best methods of learning language because we can see better when we try to set up sentences." L6 has a different point of view from all the previous comments with greater appreciation for grammar instruction and learning. This suggests that the variety of individual students in any one class will result in differing preferences for the method of learning new information.

\section{L7: "I don't like Grammar."}

L8: "it should be supported with speaking activities." L8's comment indicates that he/she prefers an integration of grammar instruction into communicative activities.

L9: "I would appreciate using games for learning grammar."

L10: "we should use grammar in action," suggestive of learning grammar in a communication atmosphere where students are encouraged to interact socially and collectively with each other, much like outside of the classroom environment.

Amongst the ten comments we received from the learners, only L6 showed preference for grammar to be taught using the isolated method. As he commented, "learning grammar is one of the best methods of learning language because we can see better when we try to set up sentences." All the other comments showed clear preference for the integrated approach.

The quantitative and qualitative data provided by the learners strongly indicate that the integrated approach of FFI is preferred over the isolated one. The statistical test gives evidence that this preference is statistically significant. 
The study's main aim, as mentioned earlier, was to compare between the integrated and the isolated types of FFI in terms of preference among learners and teachers. A secondary aim was to find out wither teachers and learners have similar or deferent preference for the timing of FFI.

The quantitative and the qualitative data results for learners show that there is a clear preference for integrated FFI. The mean results for the integrated set of questions $(\mathrm{M}=3.50)$ is higher than that the isolated one $(\mathrm{M}=3.23)$. the Statistical analysis test showed that this deference is statistically significant: $(\mathrm{P}=0.00)$. In the qualitative section of the results, nine out of ten learners $(90 \%)$ stated their preference for the integrated approach. Therefore, learners' data, states a clear preference for the integrated approach over the isolated one. However, the mean of the isolated items is still high (3.23) which indicates that learners strongly value isolated FFI.

The results of analyzing the teachers' quantitative data conveyed a strong preference for integrated FFI. It showed a higher difference between the two means of the integrated and isolated data sets: integrated $(\mathrm{M}=2.98)$, isolated $(\mathrm{M}=1.98)$, and the statistical test supported this statement: $(\mathrm{p}=$ 0.00). Although the quantitative data showed a clear preference for integrated FFI, the qualitative results showed that five out of eight teachers who commented on the topic see that both types integrated and isolated are equally important whilst three out of eight preferred the integrated FFI. The findings of this study are in line with the research made by Valeo and Spada (2015) where the findings showed a significant preference for integrated FFI, at the same time learners and teachers valued isolated FFI. They are also in line with the findings of the study made by Bulut and Algül (2017), where the findings showed that learners preferred integrated FFI and valued isolated FFI.

\section{Conclusion and Recommendation}

FFI is basically inserting grammatical structures teaching into the communicative-based classes. The two ways of FFI, isolated and integrated, are ways of attracting the learners' attention to the grammatical features of the language while the main focus is communicative activities.

The study in this paper investigated the difference between the two types of FFI in term of learners and teacher's preferences. The two questions of this thesis were, what type of FFI do teachers and learners prefer, isolated or Integrated? And is there any difference between teachers and learners' preferences between the two types of FFI?

The research in this paper is a descriptive one, based on a survey method. Two different questionnaires were used, one for teachers and one for learners. Teachers and learners were asked to respond to a set of statements in 5-point Likert scale and each questionnaire had one open ended question where participants could add their own comments on the topic. The study was applied in Istanbul Aydin University-Preparatory School. All learners were adults FLLs of English and all teachers were FLTs.

Both qualitative and the quantitative data obtained from the learners indicate a clear preference for integrated FFI. For the teachers' questionnaire findings, the quantitative results showed clear preference for Integrated FFI, while the quantitative results showed that an eclectic approach is preferred. The statistical test showed that the quantitative data findings are statistically significant. These findings are in line with the findings of Valeo and Spada (2015), and Bulut and Algül (2017). 
These also indicate that both the learners and teachers value isolated FFI. The mean of the learners' isolated items is (3.23), and that of the teachers is (1.98); this remarkable difference may indicate that the learners valued isolated FFI more than the teachers. One more point to be mentioned here can be that the learners' two means, the isolated and the integrated, refer to the option strongly agree in the 5-points Likert scale used in the questionnaire - integrated (3.50) and isolated (3.23) which means that the learners strongly value isolated FFI even though they do prefer integrated FFI more.

Based on these findings, it can be proposed that an eclectic approach may be more beneficial. The findings of this study showed that both the learners and teachers valued both types, but preferred the integrated FFI. Thus, for further research, an experimental study can be conducted to see the benefit of such an eclectic way.

\section{Acknowledgement}

First of all, I want to thank my supervisor Prof. Dr. Türkay Bulut for her invaluable guidance and for being a source of inspiration. Second of all, I would like to thank Evelyn Hogan for all the support and all the time she dedicated for me. She was vital source of support and motivation, I am really grateful for everything you have done Evelyn. I would also like to thank Prof. Dr. Necmiye Karataş the director of English Preparatory School at Istanbul Aydin University.

\section{References}

[1] Bulut, T., \& Algül, Ö. (2017, May). Learner Preferencees of Form-focused Instruction: Isolated or Integrated. The Journal of Academic Social Science, 5(45), 13-26.

[2] Dekeyser, R. M. (1998). Byong Focus on Form . In C. Doughty, \& J. Williams, Focus on Form in Classroom Second Language Acquisition . New York, US : Cambridge University .

[3] Doughty, C. (2001). Psychological underpinnings of a focus on form. In P. Robinson (Ed.), Cognition and Second Language Instruction. Cambridge Apolied Linguistics .

[4] Doughty, C., \& Williams, J. (1998). Focus on Form in Classrom Second language Acquisition . Cambridge University Press .

[5] Ellis, R. (1984). Classroom Second Language Development. . Oxford: Pergamon. .

[6] Ellis, R. (2001). Introduction: Investigating Form-Focused Instruction . Language Learning , 51(s1), 1-46.

[7] Ellis, R. (2006). Current Issues in the Teaching of Grammar: An SLA Perspective. tesol, 40(1), pp. 83-107.

[8] Ellis, R. (2016). Anniversary article Focus on form: A critical review. Language Teaching Research, 20(3), 405-428.

[9] Krashen, S. D. (1981). Second Language Acquisitionand and Second Language Learning . Oxford university press.

[10] Larsen-Freeman, D. (1997). On the teaching and learning of grammar: Challenging the myths. Second language acquisition theory and pedagogy. Washington, DC: ERIC Clearinghouse on Languages and Linguistics.

[11] Long, M. (1991). Focus on Form: A Design Feature in Language Teaching Methodology. In K. G. De Bot (Ed.), Foreign Language Research in Cross-Cultural Perspectives (pp. 39-52). John Benjamins.

[12] Norris, J. M., \& Ortega, L. (2000). Effectiveness of L2 Instruction: A Research Synthesis and Quantitative Meta-analysis. Language Learning , 50(3), 417-528. 
[13] Raimes, A. (2002). Errors: Windows into the mind. In G. DeLuca, M.-A. Johnson, \& M. Kogen (Eds.), Dialogue on writing: Rethinking ESL, basic writing, and first-year composition (pp. 279287).

[14] Richards, J. C. (2006). Communicative Language Teaching Today. United States of America: Cambridge University Press.

[15] Schouwstra, M. (2012). www.lotpublications.nl. Retrieved from www.lotpublications.nl: https://www.lotpublications.nl/Documents/312_fulltext.pdf

[16] Spada, N. (2017, May). Form-focused instruction: An interview with Nina Spada. Argentinian Journal of Applied Linguistics, 5(1), pp. 6-14.

[17] Spada, N. (2017). Isolating or integrating attention to form in communicative instruction: A dilemma? Babel, 53(1).

[18] Spada, N., \& Lightbown, P. (2008). Form-Focused Instruction: Isolated or Integrated? TESOL Quarterly, 42(2), 181-207.

[19] Spada, N., \& Tomita, Y. (2010). Interactions Between Type of Instruction and Type of Language Feature: A Meta-Analysis. Language Learning , 60(2), 263-308.

[20] Spada, N., Jessop, L., Tomita, Y., Suzuki, W., \& Valeo, A. (2014). Isolated and Integrated formfocused instruction: Effects on different types of L2 knowledge. Language Teaching Research, 18(4), 453-473.

[21] Valeo, A., \& Spada, N. (2015). Is There a Better Time to Focus on Form? Teacher and Learner Views. TESOL Quarterly, 50(2), 314-339.

[22] VanPatten, B. (1990, Septemper). Attending to Form and Content in the Input: An Experiment in Consciousness . Studies in Second Language Acquisition, 12(3), 287-301.

[23] Yıldırım, S., \& Yıldırım, Ö. (2016, 11 17). The importance of listening in language learning and listening comprehension problems experienced by language learners: A literature review. 16, 20942110 .

\footnotetext{
*Corresponding author.

E-mail address: hussam.abdulaziz@ hotmail.com
} 